2-13-2017

\title{
Mechanical Models Favor a Ramp Geometry for the Ventura-Pitas Point Fault, California
}

Scott T. Marshall

Appalachian State University

Gareth J. Funning

University of California, Riverside

Hannah E. Kreuger

Appalachian State University

Susan E. Owen

Jet Propulsion Laboratory, Pasadena, CA

John P. Loveless

Smith College, jloveles@smith.edu

Follow this and additional works at: https://scholarworks.smith.edu/geo_facpubs

Part of the Geology Commons

\section{Recommended Citation}

Marshall, Scott T.; Funning, Gareth J.; Kreuger, Hannah E.; Owen, Susan E.; and Loveless, John P., "Mechanical Models Favor a Ramp Geometry for the Ventura-Pitas Point Fault, California" (2017). Geosciences: Faculty Publications, Smith College, Northampton, MA. https://scholarworks.smith.edu/geo_facpubs/3 
1 Mechanical models favor a ramp geometry for the Ventura-Pitas Point fault, California

3 Scott T. Marshall ${ }^{1}$, Gareth J. Funning ${ }^{2}$, Hannah E. Krueger ${ }^{1}$, Susan E. Owen ${ }^{3}$, and John P. Loveless ${ }^{4}$

$4{ }^{1}$ Department of Geology, Appalachian State University, Boone NC, ${ }^{2}$ Department of Earth Sciences, University of California,

5 Riverside, ${ }^{3}$ Jet Propulsion Laboratory, Pasadena, CA, ${ }^{4}$ Department of Geosciences, Smith College, Northampton, MA

\section{$7 \quad$ Key Points}

8 - Two models proposed for Ventura-Pitas Point fault are tested using mechanical models: 1)

9 ramp model and 2) a constant dip model.

10 - Models of the ramp geometry for the Ventura-Pitas Point fault system better fit geologic slip

11 rate and vertical GPS deformation patterns.

12 - Mechanical models of the SCEC CFM5.0 fit regional slip rate data better than previous CFM 13 versions.

14 


\section{Abstract}

Recent investigations have provided new and significantly revised constraints on the

18 subsurface structure of the Ventura-Pitas Point fault system in southern California; however, few

19 data directly constrain fault surfaces below $\sim 6 \mathrm{~km}$ depth. Here, we use geometrically complex

20 three-dimensional mechanical models driven by current geodetic strain rates to test two proposed

21 subsurface models of the fault system. We find that the model that incorporates a ramp geometry

22 for the Ventura-Pitas Point fault better reproduces both the regional long term geologic slip rate

23 data and interseismic GPS observations of uplift in the Santa Ynez Mountains. The model-

24 calculated average reverse slip rate for the Ventura-Pitas Point fault is $3.5 \pm 0.3 \mathrm{~mm} / \mathrm{yr}$, although

25 slip rates are spatially variable on the fault surface with $>8 \mathrm{~mm} / \mathrm{yr}$ predicted on portions of the

26 lower ramp section at depth.

\section{Introduction}

Awareness of the hazards associated with continental thrust faults has increased

30 considerably in recent years, following recent damaging thrust earthquakes including the 1994

31 M6.7 Northridge, 1999 M7.6 Chi Chi, 2005 M7.5 Kashmir, 2008 M7.9 Wenchuan, 2015 M7.8

32 Gorkha, and the 2016 M7.8 Kaikoura events. Notably, the 2008 M7.9 Wenchuan event involved

33 coordinated rupture on multiple geometrically-complex thrust segments [Shen et al., 2009; Xu et

34 al., 2009; Hubbard et al., 2010]. Evidence for several large magnitude ( M8) multi-fault

35 ruptures has recently been suggested to have occurred along the Ventura-Pitas Point fault system

36 in southern California [Hubbard et al., 2014; McAuliffe et al., 2015; Rockwell et al., 2016]. The

37 potential effects of a repeat event of this type on the densely populated urban areas of the 
Ventura and Los Angeles basins are likely severe, including strong shaking [Field, 2000],

39 tsunami formation and associated infrastructure damage and human and economic losses [Ryan

40 et al., 2015]. Therefore, detailed knowledge of the subsurface fault geometry of this system is

41 vital for accurate future hazard assessments in southern California.

The Ventura-Pitas Point fault system lies in the Western Transverse Ranges of southern

43 California amongst a network of non-planar oblique reverse faults (Figure 1). In the city of

44 Ventura, McAuliffe et al. [2015] document subsurface stratigraphic evidence for a minimum of

45 5.2-6.0 meters of uplift in the two most recent earthquake events along the Ventura fault. To the

46 west, along the coast near Pitas Point, a series of uplifted emergent marine terraces preserve

47 evidence for up to four events in the last 6,700 years, each with 7-11 meters of associated

48 coseismic uplift [Rockwell et al., 2016]. Such large magnitude coseismic uplifts imply a history

49 of $\sim$ M8.0 earthquakes which, in turn, require a long fault, capable of $\sim 10 \mathrm{~m}$ of slip per event

50 [Hubbard et al., 2014; McAuliffe et al., 2015; Rockwell et al., 2016]. Along with these recent

51 discoveries of large magnitude paleo-slip events, Hubbard et al. [2014] provide subsurface

52 geophysical evidence that the Ventura fault is structurally linked with the Pitas Point fault to the

53 west and with the San Cayetano fault to the east, forming a single through-going seismically

54 active fault surface of $>100 \mathrm{~km}$ length. Henceforth, we refer to this single continuous fault

55 surface as the Ventura-Pitas Point (VPP) fault.

Despite numerous analyses of subsurface borehole and geophysical data across the VPP

57 fault [Sarna-Wojcicki et al., 1976; Yeats, 1982; 1983; Rockwell et al., 1984; Huftile and Yeats,

58 1995; 1996; Hubbard et al., 2014], few geophysical data exist that can uniquely resolve the VPP

59 fault structure at depths $>6 \mathrm{~km}$. Thus, two distinct models have been proposed for the deep fault

60 structure. The first model, which we term the "ramp model," is based on Hubbard et al. [2014] 
61 and represents the VPP fault flattening into a nearly horizontal décollement at $\sim 7 \mathrm{~km}$ depth and

62 then steepening into a lower ramp section farther north (Figure 1). The second model, which we

63 term the "no ramp model," maintains a nearly constant dip angle as is observed in the shallow

64 portions of the fault until the fault merges with the Red Mountain fault at a depth of $10 \mathrm{~km}$

65 (Figure 1). This model is based on extending the near surface portion of the VPP fault to agree

66 with earthquake hypocenters from two recent earthquake aftershock sequences [Kammerling et

67 al., 2003]. These alternate VPP fault geometries are markedly different from past realizations of

68 the fault system [e.g. Plesch et al., 2007; Marshall et al., 2008; Marshall et al., 2013] and imply

69 different structural linkages with several other faults in the region at depth. For example, the

70 ramp model links the VPP and San Cayetano faults at depth whereas the San Cayetano fault is

71 unconnected to any other subsurface structure in the no ramp representation. Furthermore, in the

72 ramp model, the Red Mountain fault is truncated by the VPP fault, so the Red Mountain fault

73 only exists above $8 \mathrm{~km}$ depth. Because existing data cannot directly resolve the deep fault

74 structure, both Ventura-Pitas Point fault models are plausible and warrant testing with

75 independent data.

76 Here, we test the two proposed VPP fault system geometries against geologic slip rate data

77 and geodetic velocities, using an established mechanical modeling method, in order to ascertain

78 which VPP fault geometry is most compatible with both long term slip rate and short term

79 geodetic data. 


\section{Mechanical Modeling of Long-Term Slip Using Realistic Fault Geometries}

The first step in our modeling process is to produce representations of the ensemble fault

83 geometries of the two competing fault geometric models. Our modeled fault surfaces in the

84 western Transverse Ranges are based upon the Southern California Earthquake Center (SCEC)

85 Community Fault Model version 5.0 (CFM5.0), with additional modifications for the ramp and

86 no ramp cases. The CFM5.0 represents a compilation of detailed geometric information about

87 the faults in southern California based upon all available geologic, geophysical, and geodetic

88 data [Plesch et al., 2007]. As uniformity of fault element shapes is preferred for stability in our

89 numerical modeling codes, we fit meshes of tessellated near-equilateral triangular elements to

90 the CFM5.0 fault surfaces, taking care to preserve any geometrical complexities and

91 irregularities present. In total, 74 structures are represented in the two alternative fault models,

92 with over 18,000 individual triangular elements in each, and a mean element size of $\sim 3.8 \mathrm{~km}^{2}$. A

93 three-dimensional interactive version of the fault meshes, a complete fault trace map, and the

94 fault mesh numeric data are provided with the accompanying auxiliary materials (Figures S1-

95 S5), and additional details on the meshing procedure are provided in the supplementary

96 materials.

Next, we use the method of Marshall et al. [2013] to estimate the distribution of fault slip

98 on the fault ensembles, testing both the ramp and no ramp cases. We summarize the procedure

99 here, but additional details of the modeling methodology are provided in the supplementary

100 materials. The best-fitting regional-scale horizontal strain rate tensor from GPS data, with the

101 three-dimensional effects of deformation from the San Andreas fault removed [Marshall et al.,

102 2013] is resolved onto our meshed fault surfaces, using the Boundary Element Method code,

103 Poly3D [Thomas, 1993], allowing each element to slip freely. This formulation allows us to 
104 calculate distributions of fault slip that are kinematically compatible with the applied regional

105 strain rate, while simultaneously accounting for mechanical interactions between all modeled

106 fault elements. In this way, we estimate slip rates for each modeled fault element that can be

107 compared individually or collectively to geologic estimates of long-term slip rates.

The model-calculated average reverse slip rates for each fault, for both the ramp and no

109 ramp cases are compared to existing geologic estimates in Figure 2. Although our model results

110 provide a distribution of slip rates across each fault surface, for the purposes of comparison we

111 estimate a single area-weighted average slip rate and area-weighted standard deviation of slip

112 values for each surface and plot the $1 \sigma$ ranges as error bars in Figure 2. Thus, a large error bar on

113 Figure 2 represents a fault surface with large spatial variations in slip rates. We compare the

114 model calculated average slip rates with two other quantities: 1) geologic reverse slip rate

115 estimates and 2) the corresponding average reverse slip rate estimates from our earlier study

116 [Marshall et al., 2013], based on the older and significantly different CFM4.0 fault geometries

117 which lack structural connections between the VPP faults. Geologic reverse slip rate ranges are

118 taken from the UCERF3 report [Field et al., 2013; 2014] with the exceptions of the upper slip

119 bound of $1.4 \mathrm{~mm} / \mathrm{yr}$ for the Simi fault [DeVecchio et al., 2012], and the 4.4-10.5 mm/yr slip rate

120 range of the VPP [Hubbard et al., 2014]. Although most of the faults in the region are likely to

121 have an oblique component of slip [Marshall et al., 2008], there are no well-constrained long-

122 term estimates of strike-slip rates in the region. We therefore focus on comparing the existing

123 reverse slip rate estimates to the model predictions.

We find that the ramp model agrees with all of the geologic slip rate ranges within the

125 model-calculated $1 \sigma$ ranges, and that the no ramp model matches fourteen out of fifteen of the

126 geologic slip rates with the only mismatch occurring on the San Cayetano fault. Both of these 
127 CFM5.0 models fit the geologic slip rate data better the CFM4.0 model of Marshall et al. [2013],

128 which does not fit two key regional faults: the Red Mountain and VPP faults. The CFM4.0

129 model predicts slower average slip rates on the VPP fault overall than are supported by the

130 geologic data (Figure 2), and due to its small surface area (compared to CFM5.0) is likely

131 incompatible with the numerous recent discoveries of large magnitude uplift events along the

132 fault [Hubbard et al., 2014; McAuliffe et al., 2015; Rockwell et al., 2016].

133 Due to large uncertainties in the existing long-term slip rate estimates, it is not surprising

134 that all of the models fit the majority of existing slip rates within the existing ranges. To better

135 distinguish which model is most compatible with existing slip rates, we now focus on examples

136 of stark differences in model predicted slip rates between two key regional faults. In the ramp

137 model, the Red Mountain fault is truncated by the VPP fault along the horizontal ramp at a depth

138 of $\sim 7 \mathrm{~km}$, which dramatically slows down the Red Mountain fault slip rates. The no ramp model

139 predicts much faster slip rates for the Red Mountain fault because the VPP fault is truncated by

140 the Red Mountain fault at $10 \mathrm{~km}$ depth. In essence, the ramp model geometry suggests that the

141 VPP fault is the master regional fault at depth, and is therefore the main driver of interseismic

142 deformation, while the no ramp model suggests the Red Mountain fault is the master fault at

143 depth. We prefer the slower slip rate of the ramp model for the Red Mountain fault because 1)

144 the Red Mountain fault does not have a clear geomorphic signature (i.e. a young sharp

145 topographic scarp), while the VPP does [McAuliffe et al., 2015], and 2) the UCERF3 preferred

146 reverse slip rate is $2 \mathrm{~mm} / \mathrm{yr}$ [Field et al., 2013], which is only within the $1 \sigma$ range of the ramp

147 model.

148 Additionally, the two CFM5.0 models predict significantly different average slip rates for

149 the San Cayetano fault (Figure 2). The ramp model predicts much faster slip rates that are closer 
150 to the UCERF3 preferred slip rate of $6 \mathrm{~mm} / \mathrm{yr}$ for the San Cayetano fault. We therefore again 151 suggest that the ramp model better fits the geologic slip rate data.

152 Long term fault slip rates throughout the western Transverse Ranges are likely to exhibit 153 significant spatial variations [e.g. Marshall et al., 2008]. Given that the long term slip rate 154 estimate of Hubbard et al. [2014] is based on data that spans only small portion of the VPP fault 155 surface, we now seek to determine which model predicts compatible slip rates at the location of 156 the existing estimate, and if the existing estimate was made in a location that should yield an 157 average value for the entire fault surface. To accomplish this, we compute the distribution of slip 158 rates at the surface of the modeled half-space, which simulates the slip that may be observed in 159 the near surface by a geologic or near-surface geophysical study. At the location of the Hubbard et al. [2014] study, both models predict local reverse slip 161 rates that are compatible with the long term slip rate estimate within the error limits (Figure 3 ). 162 Additionally, the ramp model predicts slip rates on the lower ramp section that exceed $8 \mathrm{~mm} / \mathrm{yr}$ 163 in some locations, which is compatible with the Hubbard et al. [2014] deep slip rate of 6.6-10.5 $164 \mathrm{~mm} / \mathrm{yr}$.

The Hubbard et al. [2014] slip rate estimate for the VPP fault is located near the middle of 166 the VPP fault trace where both the ramp and no ramp models predict slip rates that are faster than 167 the weighted average slip rate over the entire VPP fault surface (Figure 3). In fact, both models 168 predict the fastest near surface slip rates should occur near the location of the Hubbard et al. 169 [2014] study. According to the ramp and no ramp models, the location of the Hubbard et al. 170 [2014] slip rate estimate should yield reverse slip rates that are $15 \%$ and $79 \%$, respectively, 171 above average for the VPP fault as a whole. 


\section{3. Comparing Model-Predicted Interseismic Deformation Rates with GPS data}

174 An alternative means of testing our competing models against data is to simulate the

175 expected interseismic deformation rates for each and compare them to GPS data. Since the ramp 176 and no ramp representations use significantly different deep fault structures for the VPP and Red

177 Mountain faults, the interseismic deformation produced by these two models is distinct.

For this analysis, we use continuous GPS data from 56 stations in the Plate Boundary

179 Observatory (PBO) network provided by the MEaSUREs project (ftp://sopac-

180 ftp.ucsd.edu/pub/timeseries/measures/ats/WesternNorthAmerica/). Here, we use the minimally -

181 pre-processed daily 'raw-trended' time series data, and apply an established time series

182 processing methodology [Marshall et al., 2013; Herbert et al., 2014], which we summarize here.

183 We select GPS stations with more than two years of data since 2004, which postdates the

184 vast majority of postseismic transient motion associated with the 1999 M7.1 Hector Mine

185 earthquake [Shen et al., 2011]. To estimate secular velocities at each station, we estimate and

186 remove annual and semi-annual motions, offsets from equipment changes, common mode error

187 [Dong et al., 2006], and co- and post-seismic deformation associated with the $2010 \mathrm{M7.2}$ El

188 Mayor Cucapah earthquake [Gonzalez-Ortega et al., 2014]. To isolate the tectonic deformation

189 associated with only faults in the western Transverse Ranges region, we additionally remove

190 interseismic deformation associated with the San Andreas, San Jacinto, and Garlock faults using

191 a kinematic rectangular dislocation model using the geometry, fault slip rates, and locking depths

192 from Loveless and Meade [2011]. We discard two GPS sites in the western Transverse Ranges

193 region due to clearly anomalous vertical velocities: VNCO and P729. Both of these sites were 
194 identified by Marshall et al. [2013] as being in a zone of subsidence due to groundwater 195 extraction.

Existing studies of GPS velocities from the western Transverse Ranges region all show a 197 highly localized horizontal velocity gradient located directly above the Ventura sedimentary 198 basin [Donnellan et al., 1993a; 1993b; Hager et al., 1999; Marshall et al., 2013]. Hager et al. 199 [1999] showed that this sharp contraction gradient could be reproduced with a two-dimensional 200 finite element model with a spatially-variable low elastic modulus feature simulating the Ventura 201 sedimentary basin. As a result, Marshall et al. [2013] argue that the horizontal GPS velocities in 202 the western Transverse Ranges region are likely significantly contaminated by non-faulting203 related deformation processes acting in the Ventura sedimentary basin. Therefore, we focus here 204 on whether the ramp or no ramp models better fit the vertical GPS deformation patterns.

In order to simulate interseismic deformation, we create a second set of models where we 206 prescribe the geologic timescale model-calculated slip rate values on elements below a chosen 207 locking depth and lock all elements above that depth [Marshall et al., 2009]. These interseismic 208 forward models can then be used to predict the velocities at the locations of GPS stations. We 209 note that these interseismic models are forward models, and therefore may not fit the GPS data 210 as well as a typical inverse model; however, since the interseismic models used here are based on 211 the mechanical model calculated slip rates, we can be certain that the subsurface slip rate 212 distributions are mechanically plausible. The focus here is to determine only which model fits 213 the general patterns of vertical deformation in the region.

214 Since the GPS data are spatially sparse (Figure 4), we project the vertical velocities of 215 reliable sites within a $40 \mathrm{~km}$ wide zone onto a N20W profile that extends through the western 216 Transverse Ranges region (Figure 5). In general, the GPS profile shows $\sim 1 \mathrm{~mm} / \mathrm{yr}$ of subsidence 
217 across the Ventura basin (approximately $25-55 \mathrm{~km}$ distance on Figure 5) and $\sim 1 \mathrm{~mm} / \mathrm{yr}$ of uplift

218 to the north of the basin (60-80 $\mathrm{km}$ on Figure 5). Interseismic model predictions for locking

219 depths of 10,15 , and $20 \mathrm{~km}$ clearly show that the no ramp model produces uplift too far south

220 compared to the GPS data. On the other hand, the ramp model with a locking depth of $15 \mathrm{~km}$

221 predicts loci of relative uplift and subsidence in the approximately correct locations and therefore

222 fits the general pattern of GPS vertical deformation well overall. The under-fitting of the

223 subsidence signal (e.g. $30-55 \mathrm{~km}$ in Figure 5) is likely due to nontectonic compaction in the

224 sediments of the Ventura basin [e.g. Nicholson et al., 2007]. Therefore, we argue, that the

225 vertical GPS data favor a model that includes a shallow crustal ramp.

\section{4. Conclusions}

The CFM5.0 represents a significant update compared to previous CFM versions with

229 completely updated representations of the VPP and several other major regional faults. Based on

230 mechanical model results, CFM5.0 based mechanical models better match long term geologic

231 slip rates compared to CFM4.0 based models. With this improved deformation model, we are

232 now able to provide updated model-calculated slip rate estimates for all of the regional faults

233 within the region where our modeled boundary conditions are appropriate (Table S1,

234 supplemental materials).

Uncertainty in the deep geometry of the VPP fault has led to the proposal of two distinct 236 subsurface models (with and without a midcrustal ramp structure) in the CFM5.0. Mechanical

237 model predictions indicate that the ramp model of the VPP fault is more compatible with existing

238 regional geologic slip rate data compared to the no ramp model because the no ramp model 
239 predicts geologically unlikely slip rates along the Red Mountain and San Cayetano faults.

240 Comparisons of CFM5.0 interseismic models to vertical GPS velocities show that the no ramp

241 model predicts interseismic uplift $\sim 15 \mathrm{~km}$ too far south compared to the GPS velocities. In

242 contrast, the ramp model predicts loci of uplift and subsidence that largely agree with the data. In

243 the end, mechanical model predictions favor a ramp geometry for the VPP fault.

\section{5. Acknowledgements}

This work benefitted from constructive reviews by W. Ashley Griffith and an anonymous

247 reviewer. The authors would like to thank Judith Hubbard, John Shaw, and Andreas Plesch for

248 sharing their three-dimensional model of the Ventura-Pitas Point fault system, creating an early

249 version of the no ramp model geometry, and sharing these models the via the web. We thank

250 Craig Nicholson for guidance in creating the final no ramp model geometry. Zhen Liu and

251 Angelyn Moore provided help with GPS time series data issues, Christian Walls assisted in

252 identifying GPS sites that are recording non-tectonic motions, and Hugh Harper assisted with

253 fault meshing. Part of the research was carried out at the Jet Propulsion Laboratory, California

254 Institute of Technology, under a contract with the National Aeronautics and Space

255 Administration. This work was supported by the Southern California Earthquake Center. SCEC

256 is funded by NSF Cooperative Agreement EAR-1033462 \& USGS Cooperative Agreement

257 G12AC20038. This is SCEC contribution \#7073. All figures were produced with Generic

258 Mapping Tools [Wessel et al., 2013]. 
Carena, S., and J. Suppe (2002), Three-dimensional imaging of active structures using earthquake aftershocks: the Northridge thrust, California, Journal of Structural Geology, 24, 887-904.

Cooke, M. L., and S. T. Marshall (2006), Fault slip rates from three-dimensional models of the Los Angeles metropolitan area, California, Geophysical Research Letters, 33(L21313), 1-5.

Cooke, M. L., and L. C. Dair (2011), Simulating the recent evolution of the southern big bend of the San Andreas fault, southern California, Journal of Geophysical Research, 116(B-44-5).

Dair, L., and M. L. Cooke (2009), San Andreas fault geometry through the San Gorgonio Pass, California, Geology, $37(2), 119-122$.

DeVecchio, D. E., E. A. Keller, M. Fuchs, and L. A. Owen (2012), Late Pleistocene structural evolution of the Camarillo fold belt: Implications for lateral fault growth and seismic hazard in Southern California, Lithosphere, 4(2), 91-109.

Dong, D., P. Fang, Y. Bock, F. H. Webb, L. Prawirodirdjo, S. Kedar, and P. Jamason (2006), Spatiotemporal filtering using principal component analysis and Karhunen-Loeve expansion approaches for regional GPS network analysis, Journal of Geophysical Research, 111(B03405).

Donnellan, A., B. H. Hager, and R. W. King (1993a), Discrepancy between geological and geodetic deformation rates in the Ventura Basin, Nature, 366(6453), 333-336.

Donnellan, A., B. H. Hager, R. W. King, and T. A. Herring (1993b), Geodetic measurement of deformation in the Ventura Basin region, Southern California, Journal of Geophysical Research, 98(B12), 727-721.

Fay, N. P., and E. D. Humphreys (2005), Fault slip rates, effects of elactic heterogeneity on geodetic data, and the strength of the lower crust in the Salton Trough region, southern California, Journal of Geophysical Research, 110(B09401).

Field, E. H. (2000), A Modified Ground-Motion Attenuation Relationship for Southern California that Accounts for Detailed Site Classification and a Basin-Depth Effect, Bulletin of the Seismological Society of America, 90(6B), S209-S221.

Field, E. H., et al. (2013), Uniform California earthquake rupture forecast, version 3 (UCERF3) - The timeindependent model: Rep.

Field, E. H., et al. (2014), Uniform California Earthquake Rupture Forecast, Version 3 (UCERF3)—The Time $\square$ Independent Model, Bulletin of the Seismological Society of America, 104(3), 1122-1180.

Fuis, G. S., T. Ryberg, N. J. Godfrey, D. A. Okaya, and J. M. Murphy (2001), Crustal structure and tectonics from the Los Angeles basin to the Mojave Desert, southern California, Geology, 29(1), 15-18.

Gonzalez-Ortega, A., Y. Fialko, D. Sandwell, A. F. N.-P., J. Fletcher, J. Gonzalez-Garcia, B. Lipovsky, M. Floyd, and G. J. Funning (2014), El Mayor-Cucapah (Mw 7.2) earthquake: Early near-field postseismic deformation from InSAR and GPS observations, Journal of Geophysical Research: Solid Earth, 119(2), 1482-1497.

Griffith, W. A., and M. L. Cooke (2004), Mechanical validation of the three-dimensional intersection geometry between the Puente Hills blind-thrust system and the Whittier fault, Los Angeles, California, Bulletin of the Seismological Society of America, 94(2), 493-505.

Griffith, W. A., and M. L. Cooke (2005), How sensitive are fault slip rates in the Los Angeles Basin to tectonic boundary conditions?, Bulletin of the Seismological Society of America, 95(4), 1263-1275.

Hager, B. H., G. A. Lyzenga, A. Donnellan, and D. Dong (1999), Reconciling rapid strain accumulation with deep seismogenic fault planes in the Ventura Basin, California, Journal of Geophysical Research, 104(B11), 25,207225,219 .

Herbert, J. W., and M. L. Cooke (2012), Sensitivity of the southern San Andreas fault system to tectonic boundary conditions and fault configurations, Bulletin of the Seismological Society of America, 102(5), 2046-2062.

Herbert, J. W., M. L. Cooke, and S. T. Marshall (2014), Influence of fault connectivity on slip rates in southern California: Potential impact on discrepancies between geodetic derived and geologic slip rates, Journal of Geophysical Research: Solid Earth, 119(3), 2342-2361.

Hubbard, J., J. H. Shaw, and Y. Klinger (2010), Structural Setting of the 2008 Mw7.9 Wenchuan, China, Earthquake, Bulletin of the Seismological Society of America, 100(5B), 2713-2735.

Hubbard, J., J. H. Shaw, J. F. Dolan, T. L. Pratt, L. McAuliffe, and T. K. Rockwell (2014), Structure and seismic hazard of the Ventura Avenue anticline and Ventura fault, California: Prospect for large, multisegment ruptures in the Western Transverse Ranges, Bulletin of the Seismological Society of America, 104(3), 1070-1087. 
Hudnut, K. W., et al. (1996), Co-seismic displacements of the 1994 Northridge, California Earthquake, Bulletin of the Seismological Society of America, 86(1B), s19-S36.

Huftile, G. J., and R. S. Yeats (1995), Convergence rates across a displacement transfer zone in the western Transverse Ranges, Ventura Basin, California, Journal of Geophysical Research, 100(B2), 2043-2067.

Huftile, G. J., and R. S. Yeats (1996), Deformation rates across the Placerita (Northridge M (sub w) $=67$ aftershock zone) and Hopper Canyon segments of the western Transverse Ranges deformation belt, Bulletin of the Seismological Society of America, 86(1), 3-18.

Jolivet, R., R. Cattin, N. Chamot-Rooke, C. Lasserre, and G. Peltzer (2008), Thin-plate modeling of interseismic deformation and asymmetry across the Altyn Tagh fault zone, Geophysical Research Letters, 35(L02309).

Kammerling, M., C. C. Sorlien, and C. Nicholson (2003), 3D development of an active, oblique fault system, northern Santa Barbara Channel, CA, in Seismological Society of America Annual Meeting with Abstracts, edited.

Loveless, J. P., and B. J. Meade (2011), Stress modulation on the San Andreas fault by interseismic fault system interactions, Geology, 39(11), 1035-1038.

Magistrale, H., S. Day, R. W. Clayton, and R. Graves (2000), The SCEC southern California reference threedimensional seismic velocity model version 2, Bulletin of the Seismological Society of America, 90(6), S65-S76.

Marshall, S. T., M. L. Cooke, and S. E. Owen (2008), Effects of non-planar fault topology and mechanical interaction on fault slip distributions in the Ventura Basin, California, Bulletin of the Seismological Society of America, 98(3), 1113-1127.

Marshall, S. T., M. L. Cooke, and S. E. Owen (2009), Interseismic deformation associated with three-dimensional faults in the greater Los Angeles region, California, Journal of Geophysical Research, 114(B12403), 1-17.

Marshall, S. T., G. J. Funning, and S. E. Owen (2013), Fault slip rates and interseismic deformation in the western Transverse Ranges, CA, Journal of Geophysical Research, 118, 4511-4534.

McAuliffe, L. J., J. F. Dolan, E. J. Rhodes, J. Hubbard, J. H. Shaw, and T. L. Pratt (2015), Paleoseismologic evidence for large-magnitude (Mw 7.5-8.0) earthquakes on the Ventura blind thrust fault: Implications for multifault ruptures in the Transverse Ranges of southern California, Geosphere, 11(5), 1629-1650.

Meigs, A. J., M. L. Cooke, and S. T. Marshall (2008), Using vertical rock uplift patterns to infer and validate the three-dimensional fault configuration in the Los Angeles basin, Bulletin of the Seismological Society of America, 98(2), 106-123.

Nicholson, C., M. J. Kamerling, C. C. Sorlien, T. E. Hopps, and J.-P. Gratier (2007), Subsidence, Compaction, and Gravity Sliding: Implications for 3D Geometry, Dynamic Rupture, and Seismic Hazard of Active BasinBounding Faults in Southern California, Bulletin of the Seismological Society of America, 97(5), 1607-1620.

Plesch, A., et al. (2007), Community Fault Model (CFM) for Southern California, Bulletin of the Seismological Society of America, 97, 1793-1802.

Rockwell, T. K., E. A. Keller, M. N. Clark, and D. L. Johnson (1984), Chronology and rates of faulting of Ventura River terraces, California, Geological Society of America Bulletin, 95, 1466-1474.

Rockwell, T. K., K. Clark, L. Gamble, M. Oskin, E. C. Haaker, and G. L. Kennedy (2016), Large Transverse Ranges earthquakes cause coastal upheaval near Ventura, southern California, Bulletin of the Seismological Society of America, 106(6).

Ryan, K. J., E. L. Geist, M. Barall, and D. D. Oglesby (2015), Dynamic models of an earthquake and tsunami offshore Ventura, California, Geophysical Research Letters, 42(16), 6599-6606.

Sarna-Wojcicki, A. M., K. M. Williams, and R. F. Yerkes (1976), Geology of the Ventura fault, Ventura County, California, U.S. Geological Survey.

Savage, J. C. (1983), A dislocation model of strain accumulation and release at a subduction zone, Journal of Geophysical Research, 88(B6), 4984-4996.

Shen, Z. K., D. D. Jackson, and B. X. Ge (1996), Crustal deformation across and beyond the Los Angeles basin from geodetic measurements, Journal of Geophysical Research, 101(B12), 27,957-927-980.

Shen, Z. K., R. W. King, D. C. Agnew, M. Wang, T. A. Herring, D. Dong, and P. Fang (2011), A unified analysis of crustal motion in Southern California, 1970-2004: The SCEC crustal motion map, Journal of Geophysical Research: Solid Earth, 116(B11), B11402.

Shen, Z. K., J. Sun, P. Zhang, Y. Wan, M. Wang, R. Burgmann, Y. Zeng, W. Gan, H. Liao, and Q. Wang (2009), Slip maxima at fault junctions and rupturing of barriers during the 2008 Wenchuan earthquake, Nature Geoscience, 2(10), 718-724.

Thomas, A. L. (1993), POLY3D: A three-dimensional, polygonal element, displacement discontinuity boundary element computer program with applications to fractures, faults, and cavities in the Earth's crust, Master's thesis, $52 \mathrm{pp}$, Stanford University. 
Wald, D. J., T. H. Heaton, and K. W. Hudnut (1996), The slip history of the 1994 Northridge, California, earthquake determined from strong-motion, teleseismic, GPS, and leveling data, Bulletin of the Seismological Society of America, 86(1B), S49-S70.

Wessel, P., W. H. F. Smith, R. Scharroo, J. Luis, and F. Wobbe (2013), Generic Mapping Tools: Improved Version Released, Eos, Transactions American Geophysical Union, 94(45), 409-410.

Xu, X., X. Wen, G. Yu, G. Chen, Y. Klinger, J. Hubbard, and J. H. Shaw (2009), Coseismic reverse- and obliqueslip surface faulting generated by the $2008 \mathrm{Mw} 7.9$ Wenchuan earthquake, China, Geology, 37(6), 515-518.

Yeats, R. S. (1982), Low-shake faults of the Ventura basin, California, in Neotectonics in Southern California, edited by J. D. Cooper, pp. 3-15, Geological Society of America.

Yeats, R. S. (1983), Large-scale Quaternary detachments in Ventura Basin, southern California, Journal of Geophysical Research, 88(B1), 569-583. 

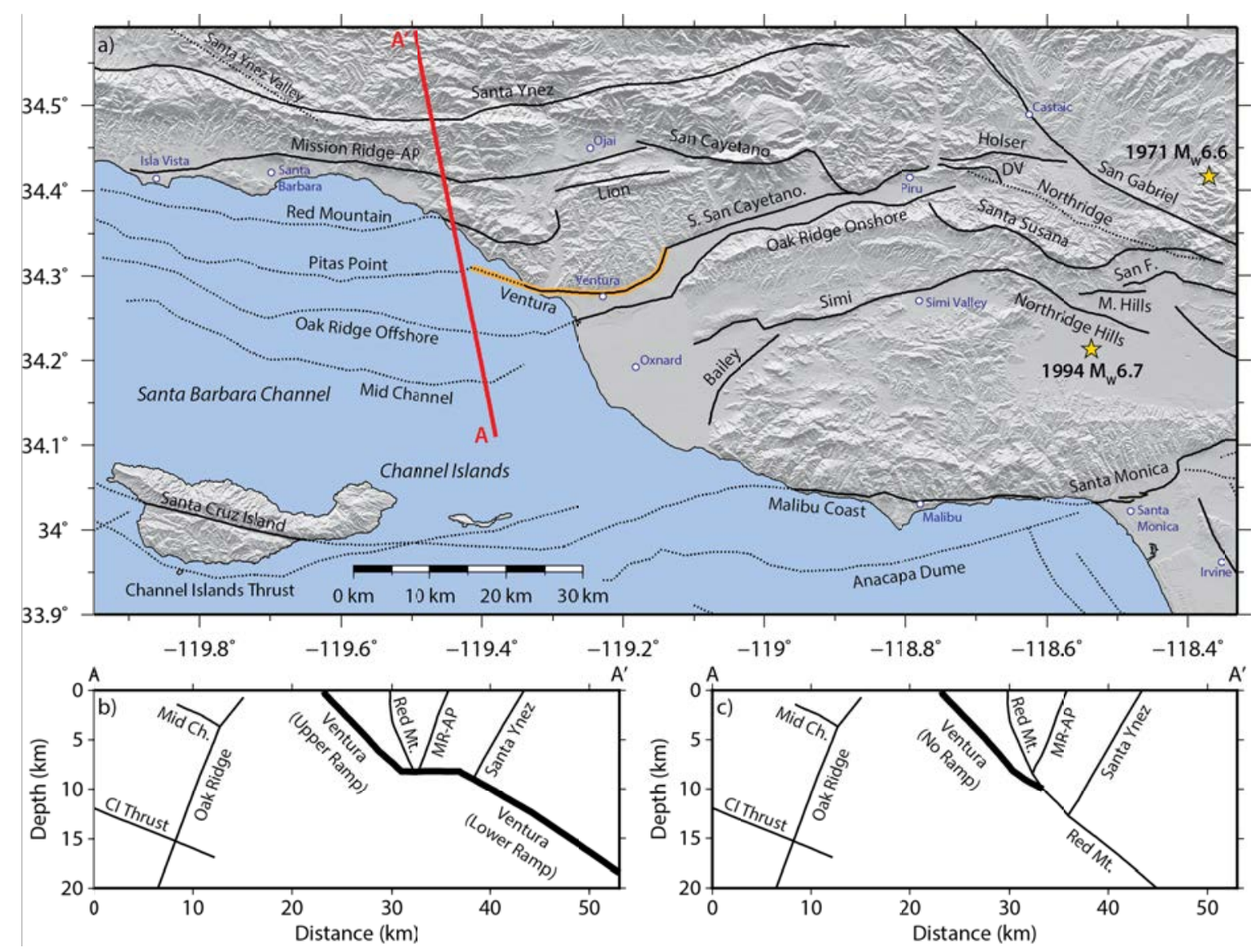

Figure 1. a) Map of modeled fault traces of the western Transverse Ranges region based on the

SCEC CFM5.0. Dashed lines indicate blind and/or offshore faults and the orange trace shows the extent of the Ventura fault in CFM4.0. Since the Pitas Point, Ventura, and South San Cayetano faults form a single through-going surface, we refer to this single surface as the Ventura-Pitas

387 Point fault. Gold stars show the epicenters of the 1971 San Fernando and 1994 Northridge earthquakes. Cross-sections through the b) ramp and c) no ramp models. Fault abbreviations are as flows: DV, Del Valle; San F., San Fernando; M. Hills, Mission Hills; Mission Ridge-AP/MR- 


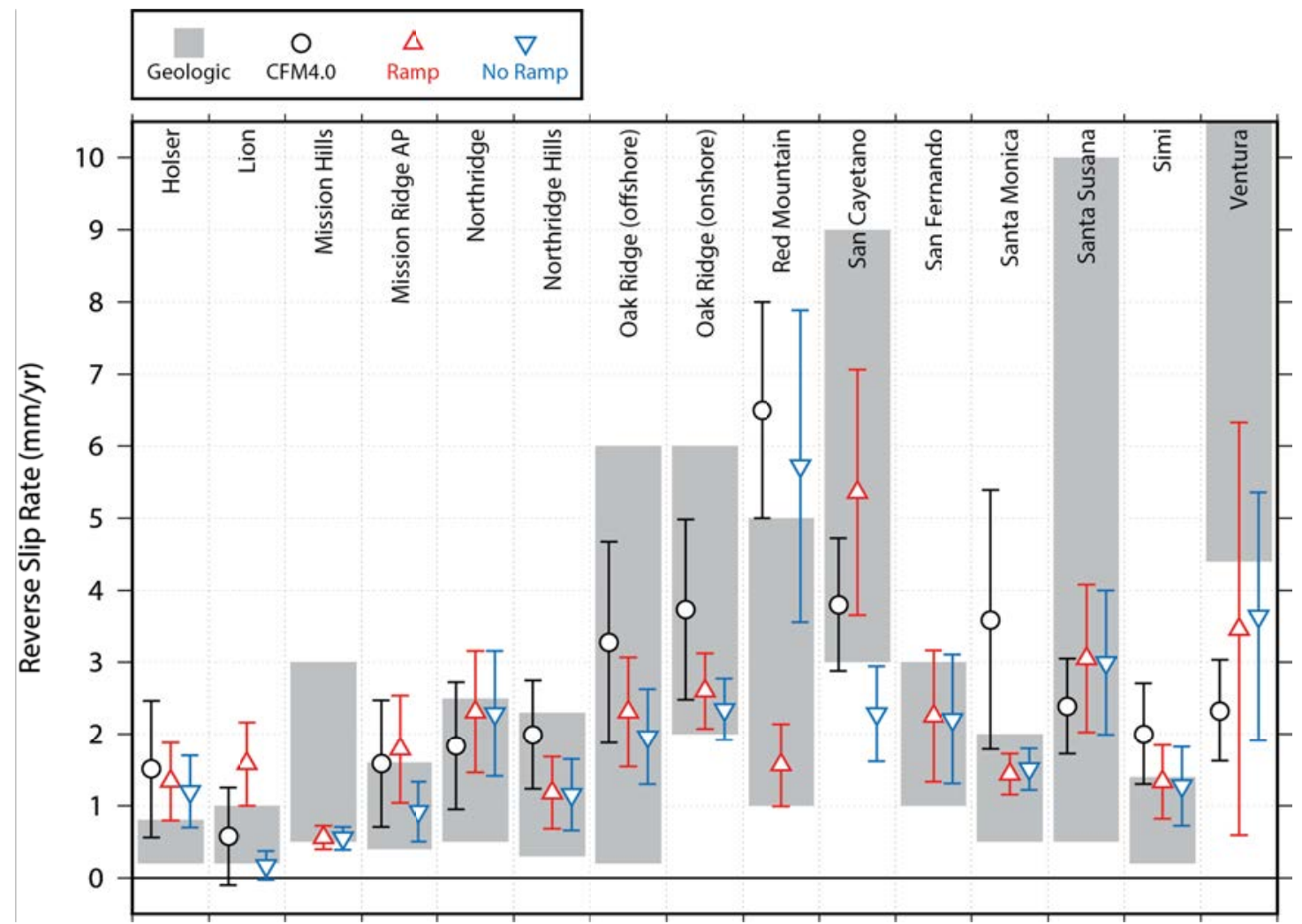

Figure 2. Model-calculated area-weighted average reverse slip rates (symbols) compared to

393 existing geologic slip rate estimates (gray rectangles) for faults in the western Transverse Ranges

394 region. For model-calculations, only elements within the seismogenic crust $(<20 \mathrm{~km}$ depth $)$ are 395 used in the calculation. 

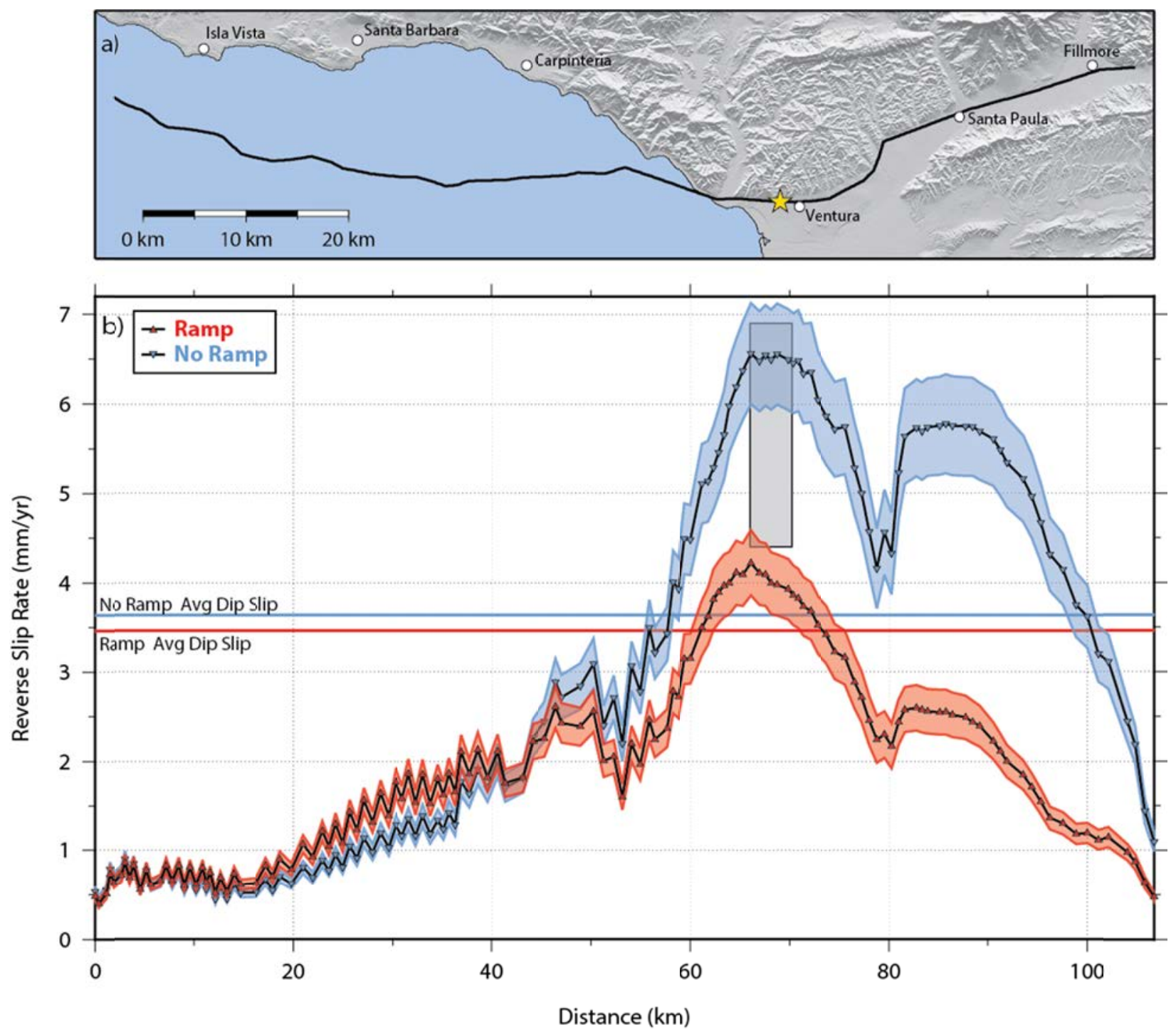

398 Figure 3. a) Fault trace map of the VPP fault. A gold star marks the location of the slip rate

399 estimate of Hubbard et al. [2014]. b) Model-predicted slip distributions at the surface of the

400 Earth for the VPP fault. The gray rectangle shows the location and reverse slip rate range

401 estimated by Hubbard et al. [2014]. The red and blue ranges reflect uncertainty in the regional

402 strain rate boundary conditions. 
403

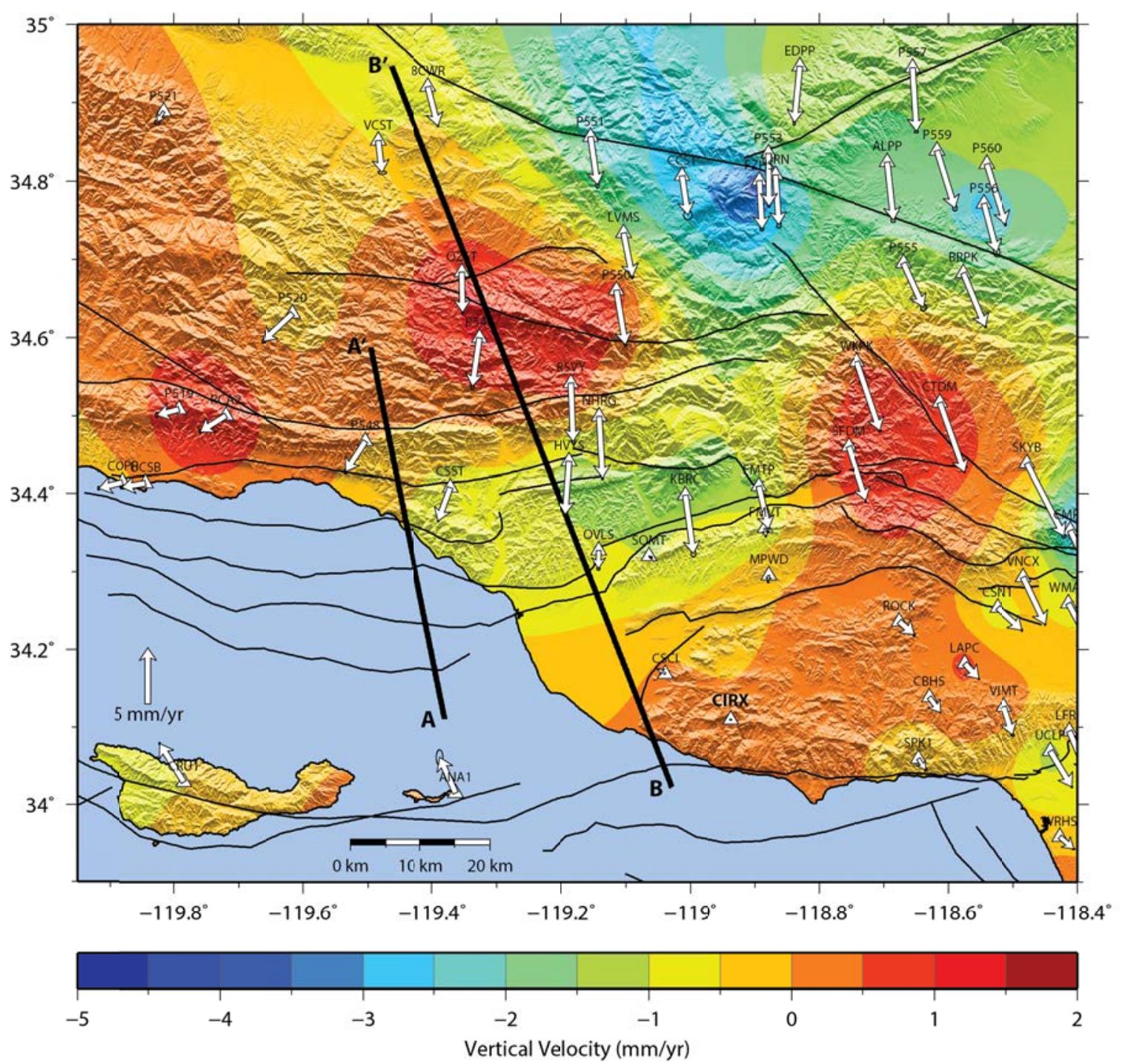

405 Figure 4. GPS horizontal (arrows) and vertical (colored contours) velocities relative to station

406 CIRX in the Santa Monica Mountains. Thick black lines indicate the location of profiles used in

407 Figure 1 (A-A') and Figure 5 (B-B'). Stations AOA1, TOST, VNCO, P729, CUHS, BKR1,

408 TABV, and P554 are excluded here due to clearly anomalous vertical velocities. 

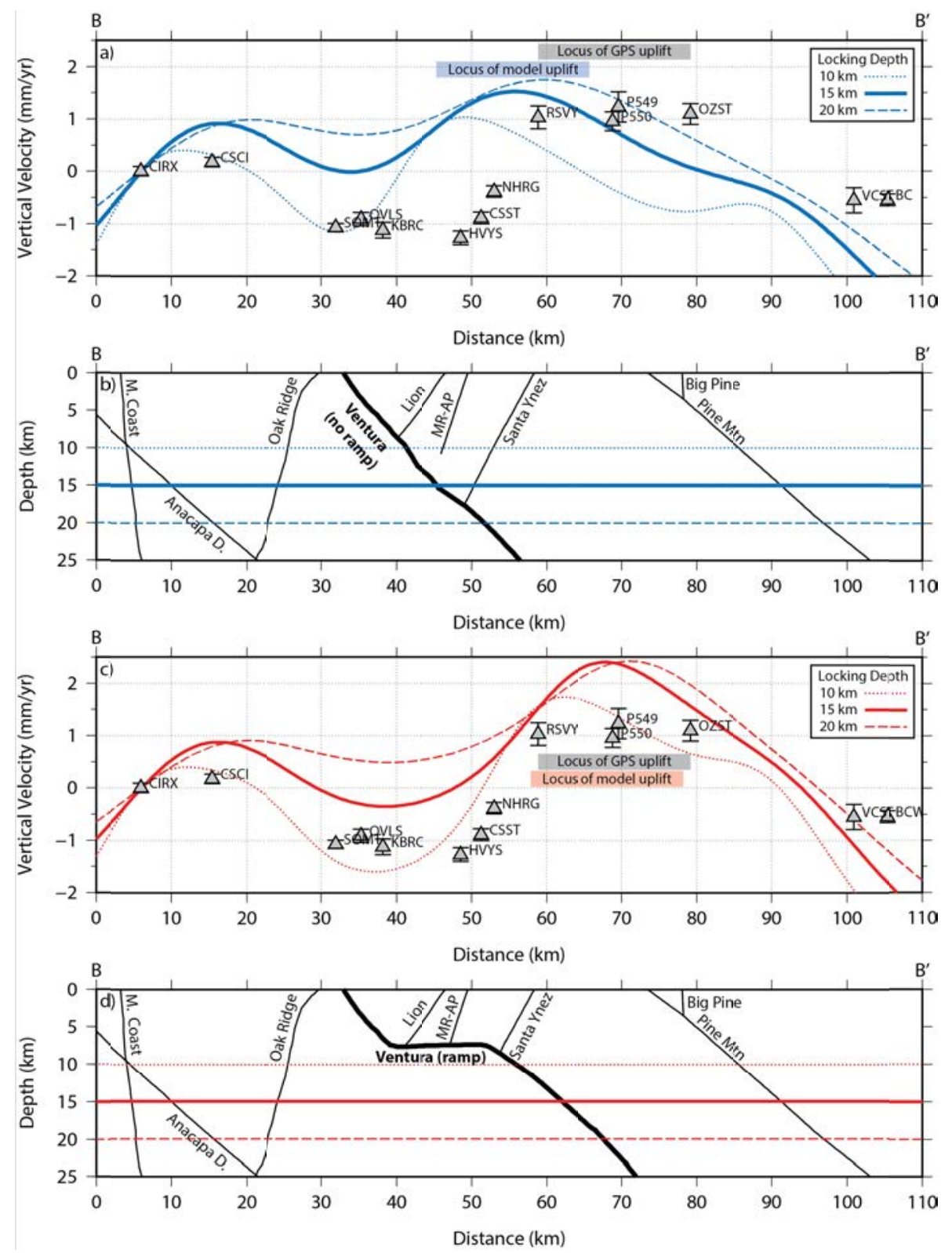

410 Figure 5. a) N20W profile through GPS vertical velocities (gray triangles) in the western

411 Transverse Ranges region. Blue curves show model predictions for the no ramp model. All

412 velocities are relative to station CIRX. b) Cross-sections through the three dimensional model

413 showing the fault geometry at the profile location. Blue horizontal lines show the three locking

414 depths plotted in part a). c-d) Same as a-b) but for the ramp model. 
Figure 1. 


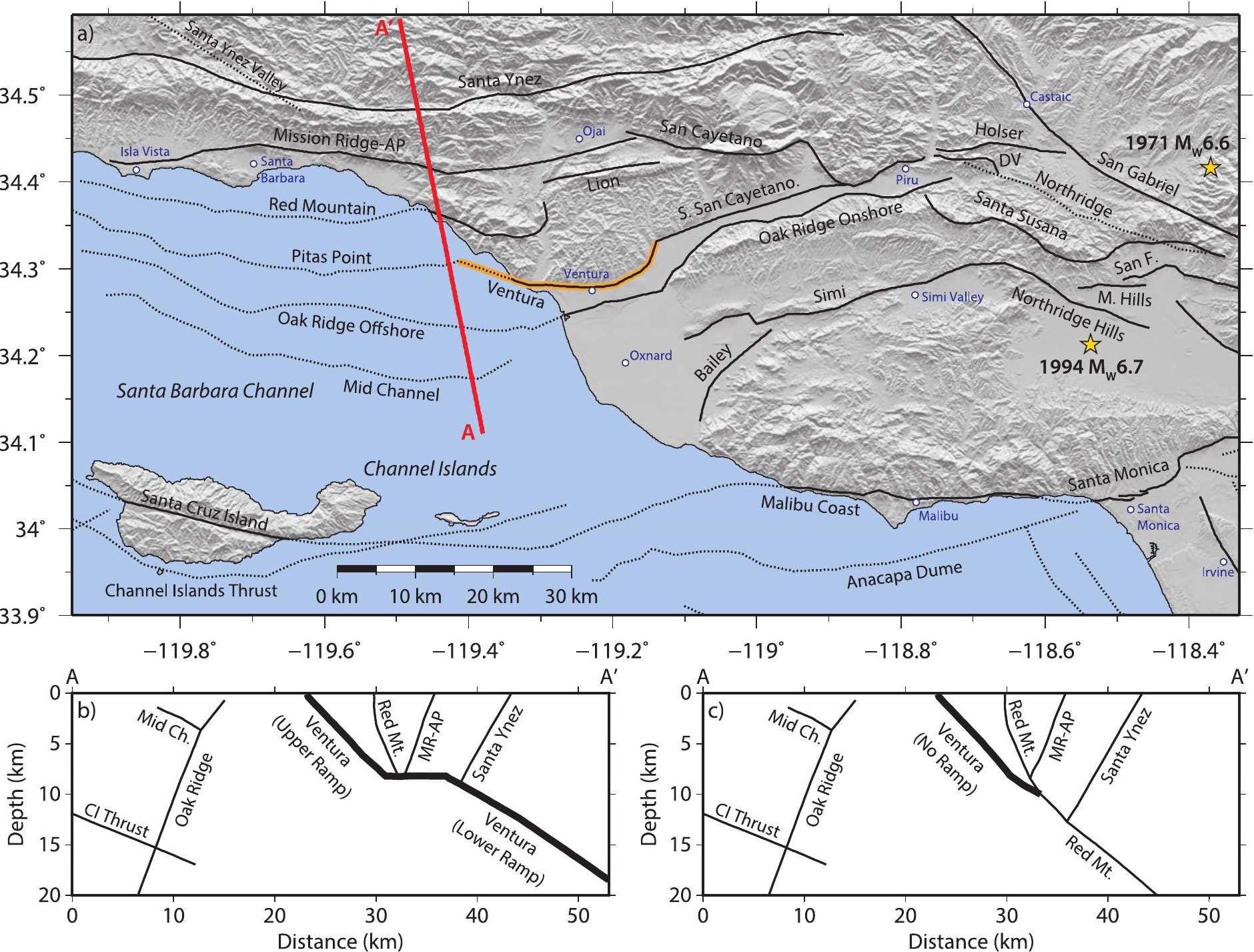


Figure 2. 


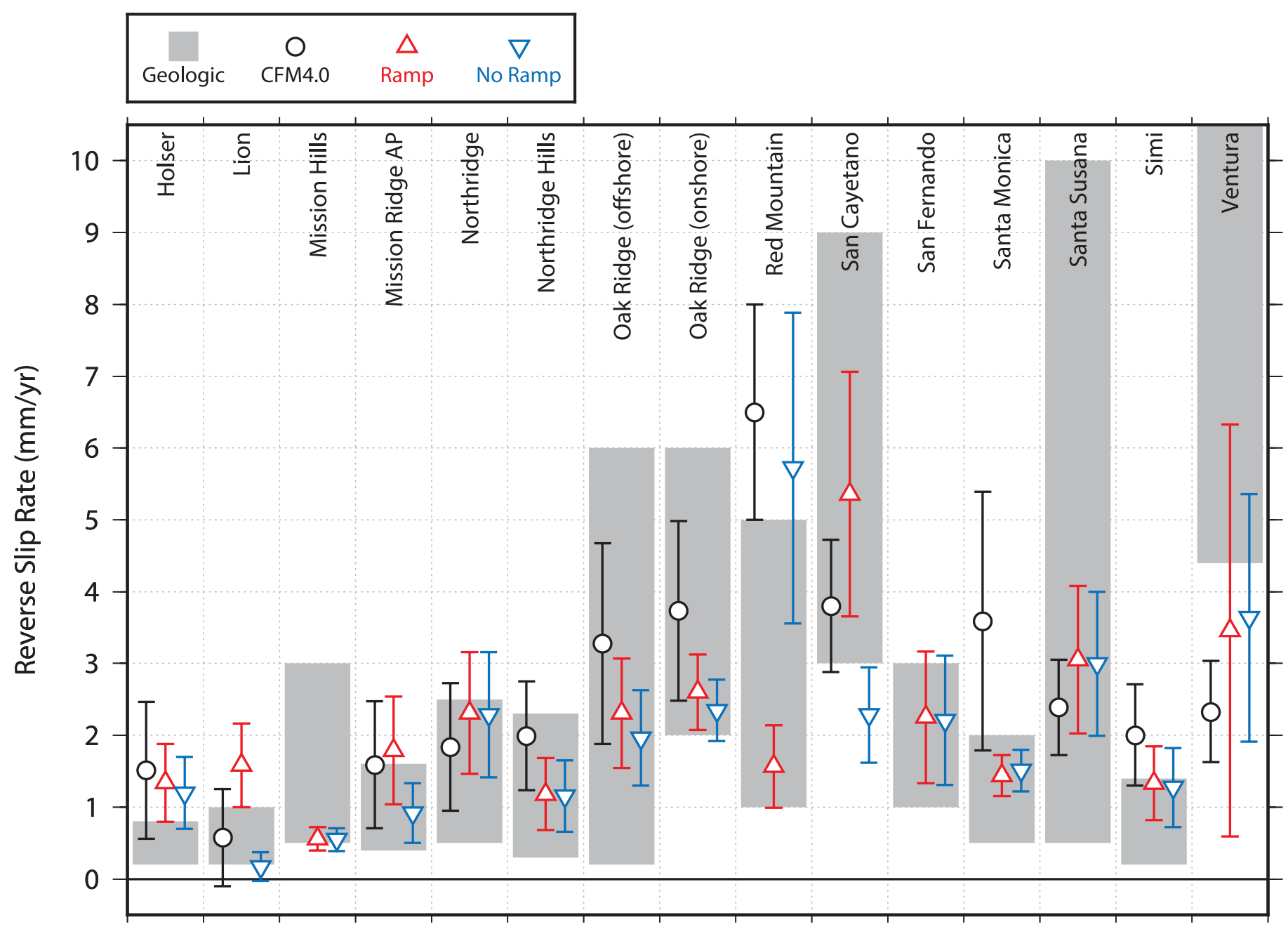


Figure 3. 

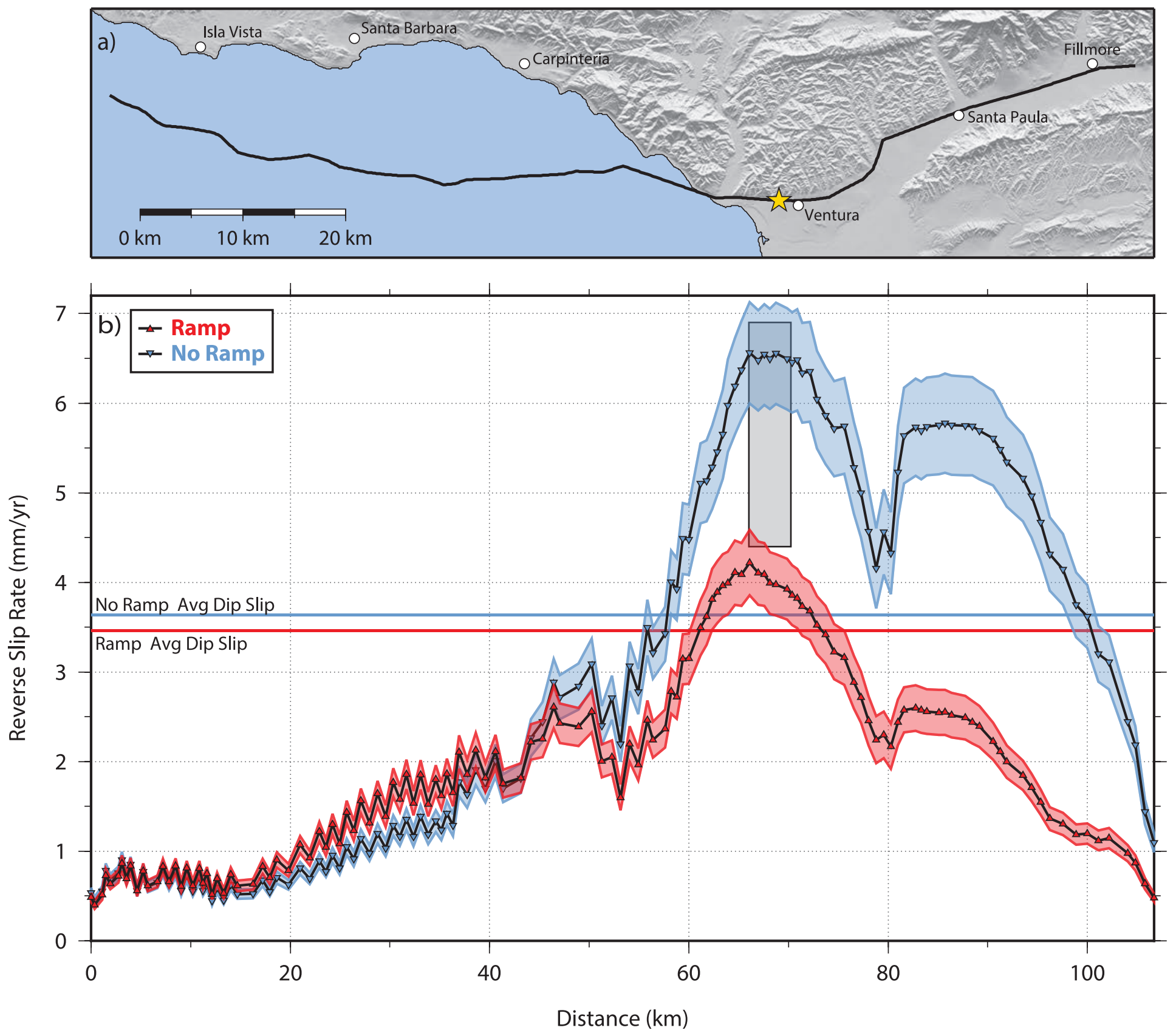
Figure 4. 

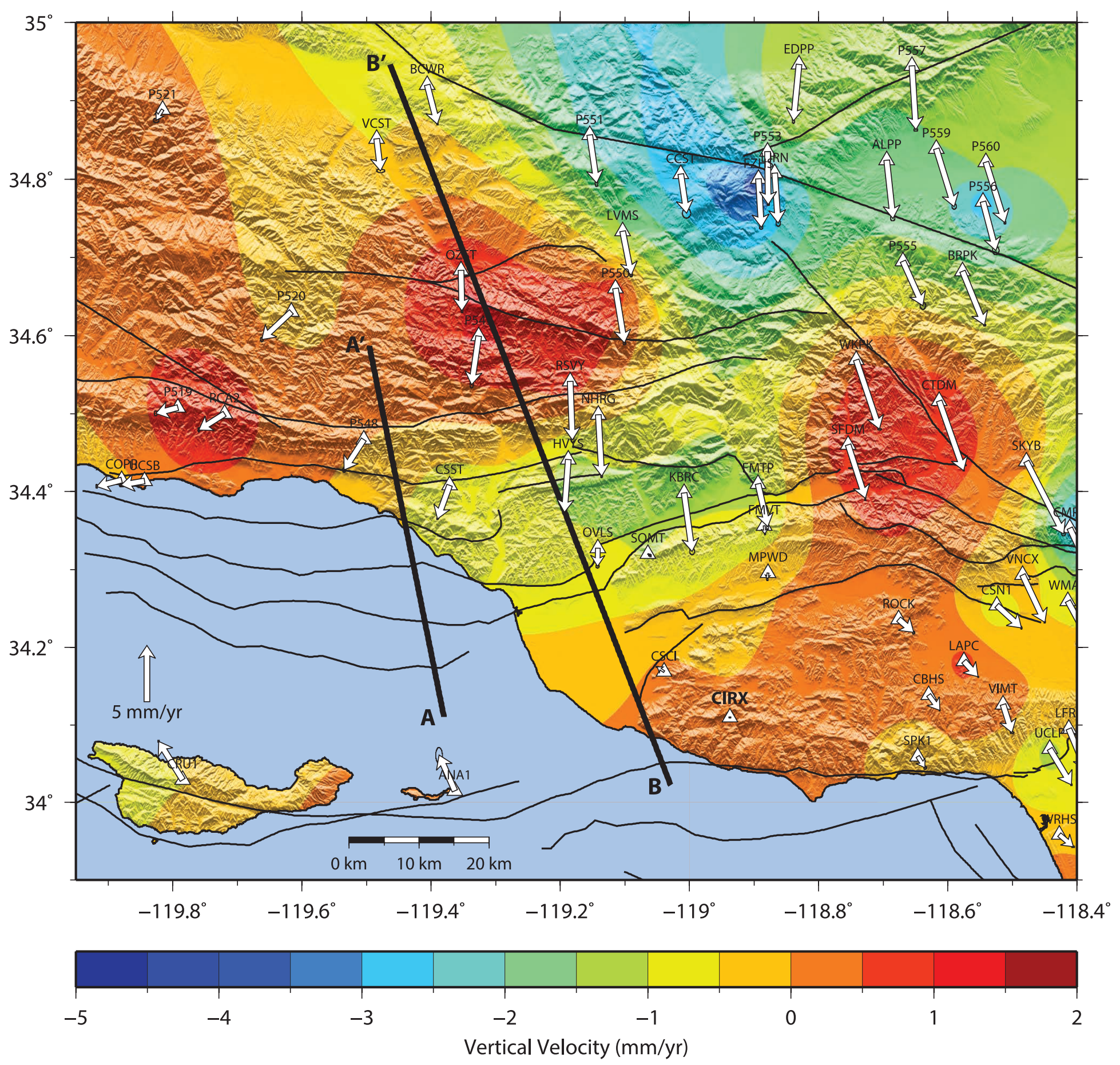
Figure 5. 


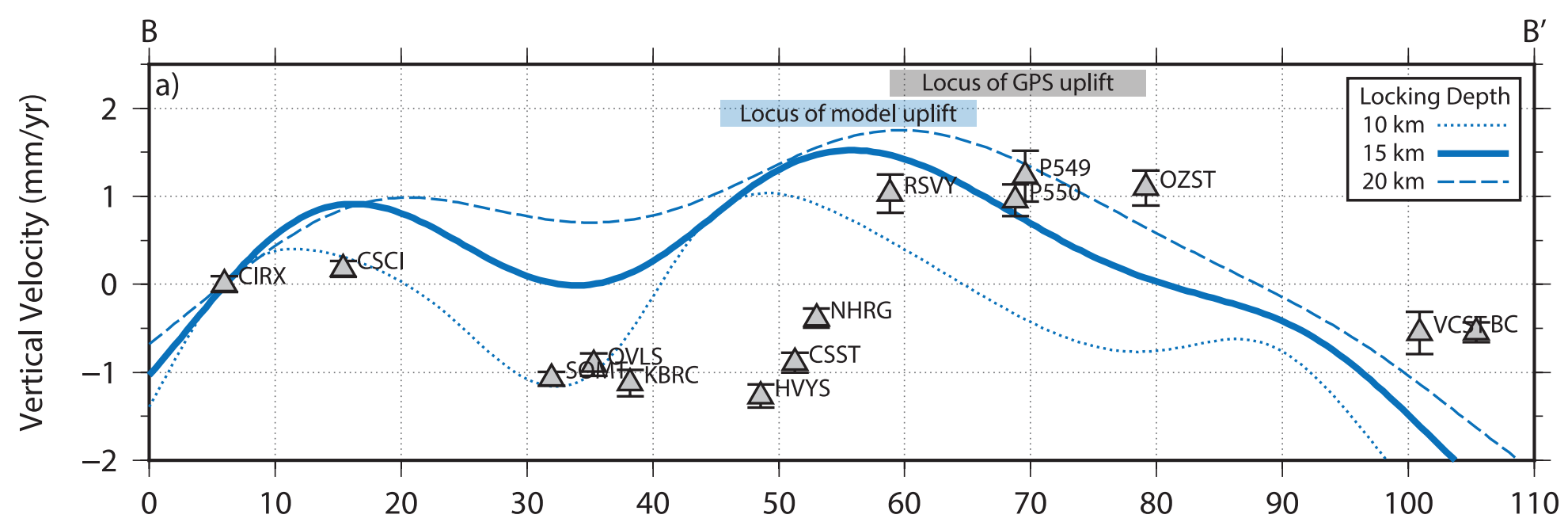

Distance (km)
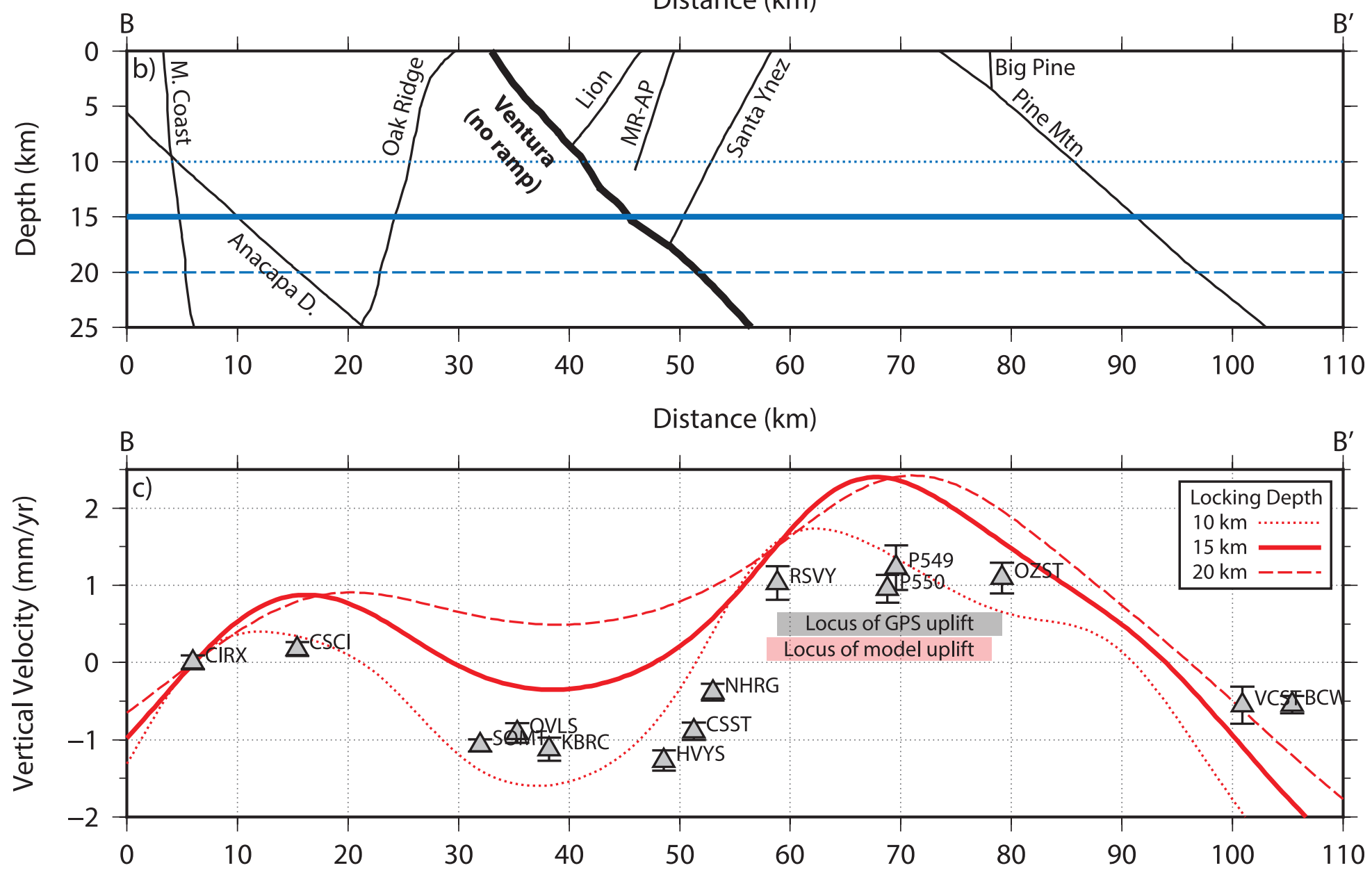

Distance (km)

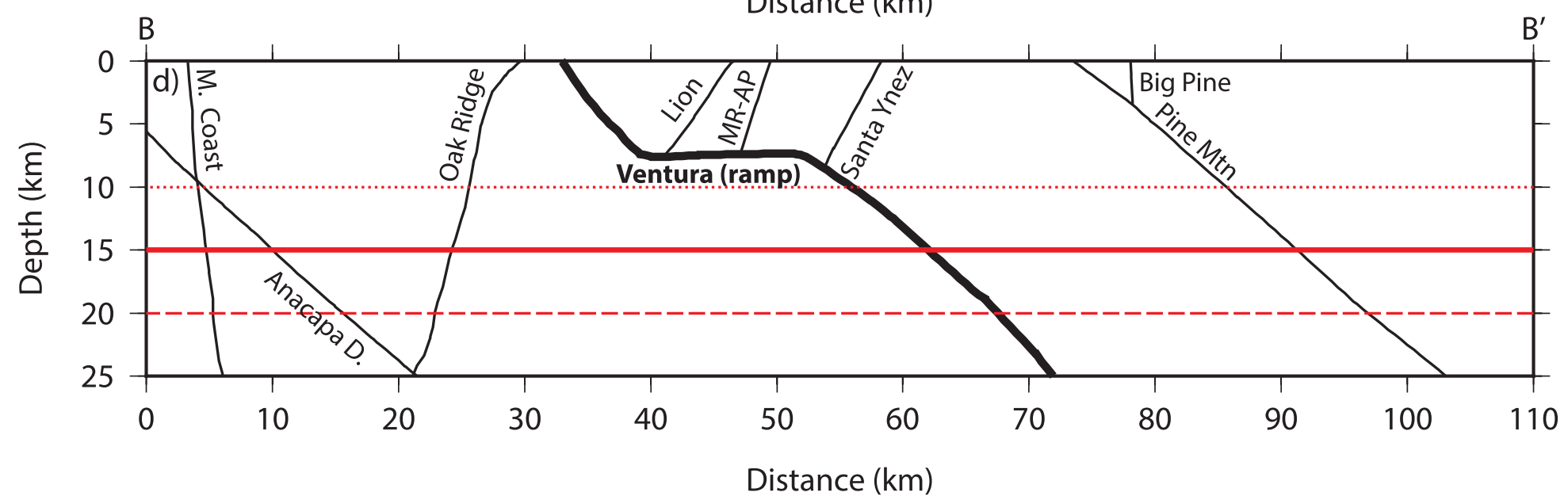

